\title{
Riset Evaluasi Gaya Komunikasi The Equalitarian Style Merry Riana Dalam Pembentukan Karakter Anak
}

\author{
Devita Obadja, Diah Ayu Candraningrum \\ devita.915150086@stu.untar.ac.id,diahc@fikom.untar.ac.id
}

Fakultas Ilmu Komunikasi Universitas Tarumanagara

\begin{abstract}
Merry Riana Learning Center is an educational service that is engaged in character building. In accordance with the name of this company, this educational service is managed by Merry Riana directly. He is a speaker, motivator, and entrepreneur. These programs are provided for children aged 8 to 19 years. To communicate with young children like that, requires its own style of communication for Merry Riana in order to establish communication with her students. The formulation of the problem in this study is how the style of communication of the equalitarian style of Merry Riana in shaping the character of their students. The purpose of this study was to find out how the communication style of Merry Riana's equalitarian style in the formation of children's character at Merry Riana Learning Center. The theory used in this study is the theory of credibility and social penetration, and uses the theory of communication style The Equalitarian Style. The type of research used is descriptive qualitative with phenomenology research strategy. The findings of this study suggest that the communication style of the equalitarian Merry Riana is ideal in establishing communication and forming the character of a child. Merry Riana establishes communication in stages by utilizing body gesture and delivering messages carried out heart to heart.
\end{abstract}

Keywords: Communication, Communication Style, Character, Equalitarian Style

\begin{abstract}
Abstrak
Merry Riana Learning Centre merupakan salah satu jasa edukasi yang bergerak di bidang pembentukan karakter. Sesuai dengan nama perusahaan, jasa edukasi ini dikelola oleh Merry Riana langsung. Beliau merupakan seorang speaker, motivator, dan seorang pengusaha. Progam-program ini disajikan bagi anak-anak usia 8 hingga 19 tahun. Untuk berkomunikasi dengan anak-anak belia seperti itu, membutuhkan gaya komunikasi tersendiri bagi Merry Riana agar dapat menjalin komunikasi dengan anak didiknya. Rumusan masalah dalam penelitian ini adalah bagaimana gaya komunikasi the equalitarian style Merry Riana dalam membentuk karakter anak didiknya. Tujuan dari penelitian ini adalah untuk mengetahui bagaimana gaya komunikasi the equalitarian style Merry Riana dalam pembentukan karakter anak di Merry Riana Learning Centre. Teori yang digunakan dalam penelitian ini adalah teori kredibilitas dan penetrasi sosial, serta menggunakan teori gaya komunikasi The Equalitarian Style. Jenis penelitian yang digunakan adalah menggunakan kualitatif deskriptif dengan strategi penelitian fenomenologi. Temuan penelitian ini menghasilkan bahwa gaya komunikasi the equalitarian Merry Riana sudah ideal dalam menjalin komunikasi dan membentuk karakter seorang anak. Merry Riana menjalin komunikasi secara bertahap dengan memanfaatkan body gesture dan penyampaian pesan yang dilakukan secara heart to heart.
\end{abstract}

Kata Kunci: Komunikasi, Gaya Komunikasi, Karakter, Equalitarian Style 


\section{Pendahuluan}

Sebagai makhluk sosial, komunikasi merupakan suatu aktivitas yang sudah ada di dalam diri setiap manusia. Oleh karena itu komunikasi merupakan sesuatu yang tidak dapat dihindari, komunikasi dapat terjadi kapan saja, dimana saja dan dengan siapa saja. Menurut Webster New Collogiate Dictionary dalam Ngalimun (2017) komunikasi adalah "suatu proses pertukaran informasi antara individu melalui lambang, tanda atau tingkah laku". Setiap manusia pasti memiliki gaya tersendiri dalam menyampaikan pesan. Setiap orang akan menggunakan gaya komunikasi yang berbeda ketika mereka sedang merasa gembira, sedih, marah, tertarik, atau bosan. Begitu juga akan berbeda saat seseorang akan berkomunikasi dengan orang yang lebih tua, sahabat baiknya, orang tidak dikenal sampai kepada anak-anak. Gaya komunikasi merupakan cara bagaimana berkomunikasi baik secara verbal dan nonverbal, meliputi cara memberi dan menerima informasi dalam situasi tertentu. Gaya komunikasi tidak dapat berlaku pada setiap manusia secara sama, tetapi gaya komunikasi bisa mencerminkan karakter pribadi dan budaya (Saphiere dalam Juarsa 2016).

Setiap lembaga pendidikan membutuhkan dan melakukan komunikasi. Setiap lembaga pendidikan merupakan sebentuk organisasi, karena di dalamnya terdapat dua orang atau lebih yang memiliki tujuan yang jelas (Harapan \& Ahmad 2016). Tidak hanya sebatas sekolah yang menyediakan kurikulum pendidikan tertentu, akan tetapi pendidikan juga dapat diberikan dalam bentuk pembentukan karakter. Karakter tersebut dapat meliputi sifat-sifat kejiwaan maupun mengenai akhlak dan budi pekerti yang baik. Hal ini juga berlaku kepada Merry Riana, beliau merupakan seorang pengusaha, penulis dan juga motivator Indonesia. Beliau lahir di Jakarta, 29 Mei 1980. Saat ini beliau mendirikan sebuah perusahaan yang bergerak di bidang jasa edukasi pembentukan karakter anak. Dimana jasa yang diberikan akan menawarkan sebagaimana pembelajaran-pembelajaran menarik yang dapat berguna dalam menunjang karakter anak yang baik. Hal ini dapat terselenggara dikarenakan beliau memiliki sebuah resolusi ingin menciptakan dampak positif bagi jutaan orang di Indonesia.

Dalam kehidupan yang terus berkembang menjadi semakin modern, perlu adanya kualitas sumber daya manusia yang tinggi. Pembelajaran pembentukan karakter ini tentu saja dapat membantu menciptakan, mempertahankan serta meningkatkan motivasi terhadap dirinya sendiri, sehingga hal ini akan berdampak terhadap kualitas hidup seseorang. Berawal dari latar belakang diatas, penelitian ini mengangkat fokus pertanyaan penelitian, "Bagaimana gaya komunikasi antarpribadi Merry Riana dalam membentuk karakter anak didiknya di Merry Riana Learning Centre?" dengan tujuan penelitian adalah untuk mengetahui bagaimana gaya komunikasi antarpribadi Merry Riana, serta untuk mengetahui apakah gaya equalitarian style yang digunakan Merry Riana efektif dalam pembentukan karakter anak di Merry Riana Learning Centre.

\section{Metode Penelitian}

Penelitian yang dilakukan oleh penulis adalah penelitian yang bersifat kualitatif deskriptif. Penulis menggunakan penelitian kualitatif deskriptif karena penulis ingin membuat deskripsi dan gambaran secara sistematis, faktual, lengkap, akurat mengenai gaya komunikasi antarpribadi (the equalitarian style) dalam proses 
pembentukan karakter anak. Pada penelitian ini, strategi penelitian yang digunakan adalah fenomenologi. Menurut Bogdan dan Taylor (dalam Nugrahani, 2014) fenomenologi merupakan analisis yang berusaha mencari pemahaman melalui cara melakukan pengamatan pastisipasi, wawancara terbuka, dan dokumen pribadi.

Subyek dari penelitian yakni narasumber penelitian ini yaitu Merry Riana sendiri. Penulis melibatkan sosok Merry Riana secara langsung sebagai narasumber penelitian ini dikarenakan sesuai dengan kajian penelitian ini, dimana penulis ingin melihat sebagaimana gaya equalitarian style Merry Riana dapat memberikan pengaruh dalam pembentukan karakter anak. Lalu peneliti juga melibatkan manager dan supervisior Merry Riana Learning Centre, serta murid atau alumni Merry Riana Learning Centre. Sedangkan untuk obyek penelitian ini sendiri adalah studi kasus mengenai penerapan gaya komunikasi The Equalitarian Style Merry Riana dalam pembentukan karakter anak di Merry Riana Learning Centre. Penulis ingin mengetahui seberapa besar dan bepengaruh gaya komunikasi antarpribadi tersebut dalam proses membentuk karakter seorang anak.

Metode pengumpulan data yang penulis gunakan dalam penelitian ini dilakukan melalui data primer dan data sekunder. Untuk data primer sendiri, penulis menggunakan metode observasi secara non-partisipan, di mana penulis hanya akan datang ke tempat penelitian namun tidak terlibat dalam kegiatan tersebut, melainkan peneliti hanya menjadi pengamat. Metode lain yang penulis gunakan adalah melalui wawancara. Penulis melakukan wawancara dengan dua cara, yaitu wawancara terstruktur dimana seluruh pertanyaan sudah penulis tulis sebelum wawancara, juga secara tidak terstruktur, dimana penulis dapat secara bebas bertanya tanpa pedoman pertanyaan. Tidak hanya menggunakan data primer saja, akan tetapi penulis juga menggunakan data sekunder dimana data ini dapat penulis peroleh selama di lapangan ataupun dari pihak informasi lainnya yang terpercaya.

Teknik pengolahan data dalam penelitian ini sendiri, penulis menggunakan teknik reduksi data, penyajian data, serta penarikan kesimpulan atau verifikasi. Miles dan Huberman (dalam Sugiyono, 2010) mengemukakan bahwa aktivitas dalam analisis dara kualitatif dilakukan secara interaktif dan berlangsung secara terus menerus sehingga datanya sudah jenuh. Lalu, untuk teknik keabsahan data penelitian ini, penulis menggunakan teknik triangulasi. Menurut Wiersma (dalam Sugiyono, 2010) triangulasi diartikan sebagai pengecekan data dari berbagai sumber dengan berbagai cara dan berbagai waktu.

\section{Hasil Temuan dan Diskusi}

Merry Riana Learning Centre pada awalnya merupakan sebuah perusahaan yang berdiri sendiri terlebih dahulu, akan tetapi seiring berkembangnya perusahaan, Merry Riana Learning Centre berubah menjadi sebuah divisi khusus yang dikepalai oleh Merry Riana Group. Merry Riana Learning Centre ini bergerak di bidang jasa edukasi pembentukan karakter. Jasa edukasi ini dikelola oleh Merry Riana langsung bersama sang suami, Alva Christopher Tjenderasa. Awal mula perusahaan ini terbentuk karena adanya resolusi Merry Riana untuk menciptakan dampak positif bagi satu juta orang. Pada saat itu, tahun 2012 Merry Riana masih sibuk pulang-pergi Indonesia-Singapore. Lalu pada tahun 2013 awal Merry Riana menetapkan keputusan untuk menetap di Indonesia dengan membawa resolusi yang ingin ia capai. Akhirnya, seiring berjalan waktu, Merry Riana berpikir bagaimana cara untuk menyalurkan resolusi beliau agar terciptanya dampak positif bagi satu juta orang 
tersebut. Akhirnya resolusi itu terbentuk melalui buku, seminar, radio, sosial media, website, TV, media cetak dan sebagainya.

Seiring berjalannya waktu, Merry Riana berpikir kembali bahwa untuk menciptakan dampak positif harus dimulai terlebih dahulu melalui anak-anak karena mereka merupakan tiang-tiang generasi bangsa. Akhirnya setelah diskusi secara terus menerus bersama sang suami dan beberapa staff pertama, terpikirkan untuk membuat sebuah tempat les. Akan tetapi, tempat les di Indonesia sudah banyak dan rata-rata mengajarkan hal yang sama, yaitu segala sesuatu yang diajarkan di sekolah. Dengan pemikiran "apakah dari nilai pelajaran saja sudah cukup untuk menjadi orang sukses, untuk menjadi orang yang benar?" jawabannya adalah tidak, akhirnya mereka memutuskan untuk membuat program di luar pembelajaran sekolah, yaitu pada bidang pembentukan karakter.

Sebelum terbentuknya Merry Riana Learning Centre, mereka memutuskan untuk membuat program anak terlebih dahulu. Program pertama yang dibuat diselenggarakan di Bandung, pada tanggal 23-28 Juni 2014. Program ini ternyata mendapatkan antusiasme yang sangat baik. Akhirnya program ini kembali diadakan pada bulan Desember 2014 dan ternyata mendapatkan hasil yang memuaskan. Melihat banyaknya partisipan dari orang tua yang menginginkan pendidikan karakter pada anaknya, akhirnya pada tahun 2015 terbentuklah Merry Riana Learning Centre pertama di Puri Indah, 2016 di BSD, 2017 di Kelapa Gading, dan 2018 di Permata Hijau dengan memusatkan seluruh kantor di Neo Soho, Jakarta.

Menurut Azehari (2015) komunikasi interpersonal dapat diartikan sebagai penggunaan bahasa atau pikiran yang terjadi di dalam diri komunikator sendiri. Dalam menjalin komunikasi dengan anak didiknya, sosok Merry Riana memerlukan gaya tersendiri untuk dapat menyalurkan pesan yang ingin ia sampaikan dengan baik. Sebagai seseorang yang selalu berhadapan dengan banyak orang dikehidupan seharihari, Merry Riana selalu membagikan sesuatu yang berdasarkan kenyataan, berdasarkan apa yang beliau lakukan. Menurut Merry Riana, ketika ia menyentuh hati seseorang untuk memberikan suatu emosi tertentu, hal itu dapat membantu secara efektif dalam proses penyampaian pesan.

Tidak hanya menggunakan effort tertentu dalam menjalin komunikasi, Merry Riana juga memiliki metode dalam menjalin komunikasi dengan anak didiknya, antara lain empower, uplift, serve, dan support. Ketika sang anak merasa tidak percaya diri, diperlukan adanya motivasi untuk meng-uplift energi tersebut, lalu setelah itu diperlukan adanya serve, melayani. Dan yang terakhir adalah support. Dari metode tersebut tentu saja dapat memberikan suatu dampak positif, karena metode yang digunakan ini merupakan metode penyampaian pesan heart to heart sehingga anak-anak pasti dapat menerima nya perlahan-lahan secara baik. 
Gambar 1. Merry Riana Saat Memberikan Pembelajaran

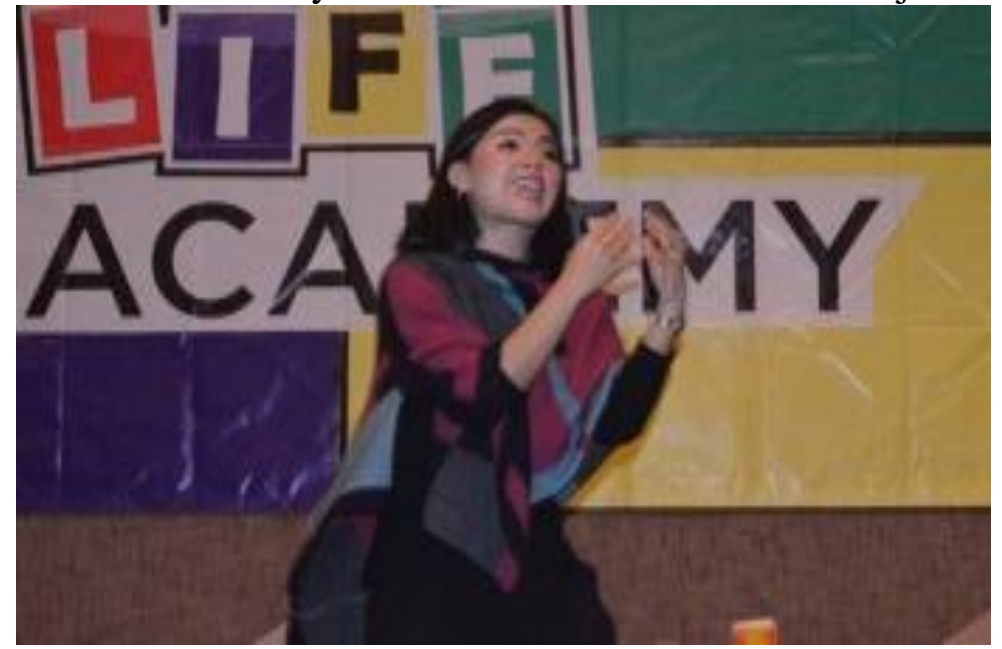

Sumber: Dokumentasi Peneliti (2018)

Merry Riana sudah dapat membuat anak didiknya untuk berani dalam menyampaikan gagasan nya serta terbuka kepada beliau. Akan tetapi sosok Merry Riana merupakan pembicara yang lebih banyak one to all daripada one on one. Merry Riana merupakan sosok pembicara aktif yang dapat memanfaatkan suasana untuk mendapatkan interaksi atau respon dari para audience-nya. Sedangkan untuk melakukan komunikasi dengan anak didiknya secara one on one, Khezia mengatakan bahwa hal itu tidak dapat dilakukan secara terus menerus secara intens dan mendalam.

Gaya komunikasi yang dilakukan Merry Riana sesuai dengan teori gaya komunikasi the equalitarian style. Dimana menurut Tubbs dan Moss dalam Ruliana (2014) gaya ini memiliki aspek penting yaitu ditandai dengan berlakunya arus penyebaran pesan yang bersifat dua arah dan memiliki arus komunikasi yang berjalan secara terbuka. Merry Riana juga merupakan sosok yang sudah memiliki kredibilitas yang baik. Berawal dari kisah hidup nya yang dianggap inspiratif hingga sampai membuat beliau menjadi seorang speaker yang kredibel. Kredibilitas beliau tidak berhenti disitu saja, dimana kredibilitas nya juga dapat dilihat dari banyaknya kepercayaan orang tua yang memilih sosok Merry Riana dalam membantu proses pembentukan karakter anak.

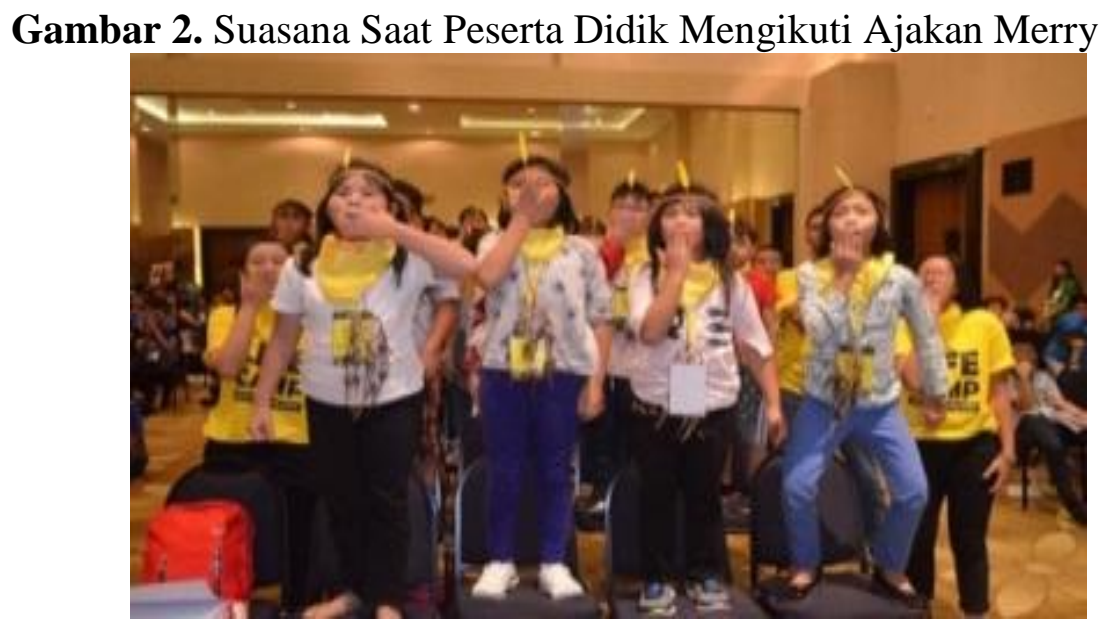

Sumber: Dokumentasi Peneliti (2018) 
Hal ini sesuai dengan yang teori kredibilitas menurut Mc-Croskey (dalam Rohim, 2009) yaitu untuk menjadi seorang komunikator yang efektif harus memiliki kredibilitas yang tinggi. Dimana bentuk kredibilitas itu terdiri dari initial credibility, yaitu kredibilitas yang diperoleh komunikator sebelum proses komunikasi berlangsung. Derived crebility, yaitu kredibilitas yang diperoleh seseorang saat komunikasi sedang berlangsung. Dan yang terakhir terminal credibility, yaitu kredibilitas yang diperoleh komunikator setelah pendengar atau pembaca mengikuti pendapatnya.

Kredibilitas Merry Riana dapat ia peroleh berdasarkan initial credibility, dimana pada saat beliau belum melakukan proses komunikasi pun orang sudah percaya dikarenakan nama beliau yang sudah dikenal banyak orang melalui kisah hidupnya. Lalu seiring berkembangnya waktu, kredibilitas Merry Riana juga dapat diperoleh melalui derived credibility, dimana kredibilitas tersebut diperoleh saat proses komunikasi sedang berlangsung. Seperti yang dapat kita lihat sekarang, dimana saat Merry Riana memberikan suatu pernyataan, ajakan, atau perkataan orang cenderung akan percaya dan merasa bahwa apa yang ia katakan merupakan suatu hal baik yang tidak mungkin merugikan. Hal ini juga dapat terbukti melalui antusias anak-anak didik Merry Riana yang selalu memberikan feedback positif atas pernyataan Merry Riana.

Tidak hanya berhenti disitu, kredibilitas Merry Riana juga semakin berkembang, dimana ia dapat memperoleh kredibilitas melalui terminal credibility. Dimana kredibilitas ini diperoleh saat seseorang mengikuti pendapat atau gagasannya. Hal ini sejalan dengan program karakter yang ia berikan, dimana ia mengajarkan pendidikan-pendidikan karakter kepada anak-anak yang ia harapkan dapat diterapkan dengan baik dalam kehidupan sehari-hari. Mengingat banyaknya respon dan testimoni positif dari para orang tua yang merasakan perubahan pada anaknya setelah mengikuti program Merry Riana Learning Centre dan bahkan mendaftarkan kembali anaknya ke dalam program karakter tersebut, tentu saja hal tersebut membuktikan bahwa apa yang dikatakan oleh Merry Riana diikuti dengan baik oleh para murid yang sudah menyelesaikan program tersebut.

Komunikasi yang dilakukan oleh Merry Riana tentu saja tidak langsung bergerak ke arah kemajuan yang bisa membawa hubungan tersebut menjadi lebih intim. Merry Riana tentu saja melakukan pendekatan untuk dapat membina suatu hubungan dengan orang lain, terutama anak-anak. Hal ini sesuai dengan teori penetrasi sosial dimana menurut Altman dan Taylor (dalam Rohim, 2009) hubungan yang tidak intim dapat bergerak menuju hubungan yang intim dikarenakan adanya keterbukaan diri. Saat melakukan komunikasi dengan anak didiknya, Merry Riana selalu dapat memanfaatkan situasi tersebut untuk dapat mengembangkan hubungan nya bersama sang anak agar dapat mengalami kemajuan. Merry Riana akan menggunakan situasi tersebut untuk dapat melakukan interaksi dalam bentuk apapun bersama sang anak.

Misalnya seperti saat Merry Riana berbicara mengenai pentingnya mempunyai mimpi, Merry Riana akan terlebih dahulu untuk membuka dirinya dengan cara menceritakan apa yang pernah ia alami semasa sekolah, bagaimana ia mengatasinya dan bagaimana ia belajar dari kesalahan tersebut. Setelah Merry Riana melakukan hal tersebut, anak-anak tersebut cenderung akan berani untuk memberikan pendapat mereka dan bahkan anak-anak tersebut yang akan secara aktif untuk membuka diri lebih intim. 
Dalam kehidupan yang semakin berkembang menjadi modern dan berkembangnya teknologi yang semakin canggih, tentu saja hal ini juga menuntut adanya kualitas sumber daya manusia yang tinggi. Untuk menciptakan hal tersebut tentu saja tidak dapat dilakukan berdasarkan teori saja, akan tetapi diperlukan adanya karakter yang baik agar dapat menciptakan kualitas sumber daya manusia yang tinggi. Hal ini yang menggerakan sosok Merry Riana untuk membuka jasa edukasi pembentukan karakter anak. Merry Riana menggunakan metode tertentu untuk dapat membentuk karakter anak, yaitu ELT (Experiential Learning Technologies). Dimana pada metode ini anak-anak akan diberikan suatu games terlebih dahulu, guna agar mereka untuk belajar merasakan pengalaman nya dahulu, bermain dahulu baru akan diberikan pembelajaran setelahnya, dan ternyata metode seperti ini cukup efektif untuk membentuk karakter si anak. Hal ini sesuai dengan pernyataan Suharjana dalam Utama (2011) yaitu:

"Untuk membentuk sebuah karakter, dapat dilakukan melalui bermain. Dimana dengan bermain, anak-anak akan lebih peka apabila telah merasakan suatu pengalaman tertentu terlebih dahulu. Aktivitas bermain mampu membawa peserta didik untuk mengembangkan dan meningkatkan kemampuan atau potensi yang dimilikinya ke arah positif dalam segi kognitif, afektif, fisik, dan psikomotorik."

Program yang disajikan oleh Merry Riana Learning Centre adalah program yang mengutamakan mengenai pembetukan karakter. Dimana karakter tersebut dapat juga meliputi tentang uang, komunikasi, kerja sama, waktu serta menjaga relasi. Dalam program yang ditawarkan oleh Merry Riana Learning Centre, anak-anak akan diberikan pengalaman lewat permainan terlebih dahulu.

\section{Simpulan}

Gaya komunikasi yang dilakukan oleh Merry Riana sudah efektif dalam proses pembentukan karakter anak. Gaya komunikasi Merry Riana ini sesuai dengan teori the equalitarian style, dimana gaya komunikasi ini memungkinkan untuk terciptanya suasana yang rileks, santai dan memiliki arus komunikasi dua arah. Saat Merry Riana hendak menyampaikan pesan yang ingin disampaikan, beliau akan menyentuh emosi lawan bicara tersebut terlebih dahulu sebelum menyampaikan pesan. Tidak lupa Merry Riana juga menggunakan beberapa body gesture sehingga tercipta suasana komunikasi yang nyaman agar dapat membuat lawan bicara untuk berani memberikan gagasan dan mencapai kesepakatan.

Kredibilitas yang dimiliki oleh Merry Riana juga sangat berpengaruh besar dalam menjalin komunikasi. Saat Merry Riana mengucapkan sesuatu orang cenderung akan tergerak dan percaya dikarenakan kredibilitas yang dimiliki. Merry Riana juga sudah melakukan pembentukan hubungan dengan anak didiknya secara baik, melalui beberapa tahap dan proses, dimana pada akhirnya hubungan tersebut bergerak mengalami kemajuan karena adanya pembukaan diri sehingga terciptanya komunikasi terbuka antara Merry Riana bersama anak didiknya. Serta, jasa edukasi pendidikan karakter seperti Merry Riana Learning Centre ternyata sangat berguna dalam proses pembentukan karakter anak. Mengingat banyak sekali anak-anak yang berkembang tanpa pembelajaran yang tepat. Salah satu metode untuk memberikan edukasi kepada anak dapat disalurkan melalui permainan, dimana biarkan anak-anak 
untuk merasakan terlebih dahulu pengalaman tersebut, lalu setelahnya diberikan pembelajaran yang berkaitan.

\section{Ucapan Terima Kasih}

Penelitian ini terwujud atas bantuan dari Merry Riana Group dan Merry Riana sendiri yang telah memberikan kesempatan kepada peneliti untuk melakukan penelitian. Rasa terimakasih yang sebesar-besarnya juga ditujukan kepada Ibu Diah Ayu Candraningrum, S.T., M.B.A., M.Si., selaku dosen pembimbing peneliti yang telah bersedia membimbing peneliti dari awal penelitian ini dilakukan hingga akhir.

\section{Daftar Pustaka}

Ahmad, Syarwani \& Harapan, Edi. (2016). Komunikasi Antarpribadi: Perilaku Insani Dalam Organisasi Pendidikan. Jakarta: PT RajaGrafindo Persada.

Azeharie, S., \& Khotimah, N. (2015). Pola Komunikasi Antarpribadi antara Guru dan Siswa di Panti Sosial Taman Penitipan Anak "Melati" Bengkulu. Pekommas, 18(3).

Ngalimun. (2017). Ilmu Komunikasi Sebuah Pengantar Praktis.Yogyakarta: Pustaka Baru Press

Rohim, Syaiful. (2009). Teori Komunikasi Perspektif, Ragam, dan Aplikasi. Jakarta: Rineka Cipta

Ruliana, Poppy. (2014). Komunikasi Organisasi: Teori dan Studi Kasus. Jakarta: PT RajaGrafindo Persada.

Sugiyono. (2010). Metode Penelitian Kuantitatif, Kualitatif dan R\&D. Bandung: Afabeta

file:///C:/Users/qwertyu/Downloads/312-956-1-PB\%20(1).pdf

Juarsa, Erwin. (2016). Gaya Komunikasi Pemimpin Divisi MIS Trias Sentosa Tbk Krian.

https://media.neliti.com/media/publications/82981-ID-gaya-komunikasi-pemimpindivisi-mis-pt-t.pdf

Nugrahani, F., \& Hum, M. (2014). Metode Penelitian Kualitatif. Solo: Cakra Books. http://digilibfkip.univetbantara.ac.id/materi/Buku.pdf 